\title{
Pengaruh Latihan Crocodile Push Up Dan Burpee Terhadap Kekuatan Otot Lengan Dan Hasil Shooting Handball Mahasiswa STKIP PGRI SUMENEP
}

\author{
Bayu Segara $^{1}$, Andun Sudijandoko ${ }^{2}$, \& Dwi Cahyo Kartiko ${ }^{3}$ \\ Program Studi Pendidikan Olahraga, Program Pascasarjana Universitas Negeri Surabaya \\ Coresponding author: bayusegara824@gmail.com
}

\begin{abstract}
Abstrak: Penelitian ini bertujuan untuk menganalisa pengaruh latihan Crocodile Push Up dan Burpee terhadap kekuatan otot lengan dan hasil Shooting Handball Mahasiswa STKIP PGRI Sumenep. Penelitian ini menggunakan pendekatan kuantitatif menggunakan quasi experiment dengan rancangan penelitian matching only design. Pengumpulan data dilakukan dengan tes kekuatan otot lengan melakukan Push Up selama 30 detik, tes hasil Flying Shooting Handball menggunakan skor pada saat pretest dan posttest. Data dianalisis secara statistik dimana uji normalitas, homogenitas, uji-t, dan Anova dikonduksikan menggunakan bantuan SPSS seri 0.22. Hasil penelitian menunjukkan bahwa rata-rata posttest $9.200>5.600$ dan $1.054>0.625$ dari rata-rata pretest. Hal ini menunjukan terdapat peningkatan yang signifikan antara pretest dan posttest terhadap Flying Shoot Shooting Handball yang dipengaruhi oleh perlakuan Crocodile push-up dan burpee terhadap Kekuatan Otot Lengan dah hasil Flying Shoot Shooting handball Mahasiswa STKIP PGRI Sumenep. Berdasarkan analisis di atas, dapat disimpulkan bahwa terdapat pengaruh latihan Crocodile Push-Up dan Burpee terhadap kekuatan otot lengan dan hasil Flying Shoot Shooting Handball Mahasiswa STKIP PGRI Sumenep.
\end{abstract}

Kata Kunci: Crocodile Pus Up, Burpee, Kekuatan Otot Lengan. Hasil Shooting Handball.

\section{PENDAHULUAN}

Olahraga adalah aktivitas yang mempunyai pengaruh signifikan terhadap kehidupan sehari-hari pada manusia. Dapat dikatakan demikian karena olahraga berhubungan dengan gerak yang tidak lepas dari aktivitas manusia. Banyak cara manusia melakukan aktivitas seperti berjalan, berlari, melompat, memukul dan melempar yang terakumulasi dalam gerak, yang membedakan gerak sehari-hari dengan gerak dalam olahraga adalah tujuannya. Mylsidayu \& Kurniawan (2015) menyebutkan ada empat dasar yang menjadi tujuan olahraga antara lain olahraga yang bertujuan untuk rekreasi, pendidikan, kebugaran jasmani, dan prestasi.

Latihan olehraga banyak jenisnya, antara lain latihan crocodile push-up. Jenis latihan ini memiliki pengaruh yang signifikan terhadap kekuatan otot lengan dan shooting handball dikarenakan lengan senantiasa melakukan kontraksi terus menerus saat melakukan latihan tersebut, dengan demikian otot lengan dituntut untuk bekerja terus menerus karena dalam melakukan latihan ini harus berkelanjutan (Putra, 2016). Dalam penelitian Haris (2020) menyebutkan bahwa proses latihan kombinasi burpee dan crocodile push-up memiliki beberapa manfaat saat digunakan untuk pelatihan, termasuk untuk meningkatkan kekuatan otot-otot lengan dan otot-otot kaki untuk mendukung prestasi seorang atlet.

Menurut Sridadi \& Utama (2016) bola tangan (handball) dimainkan oleh pemain yang berjumlah enam orang dan satu penjaga gawang. Obyek dari permainan ini ialah melempar bola sampai masuk menjadi gol di gawang lawan. Bola tangan dimainkan di atas lapangan dengan panjang $40 \mathrm{~m}$ dan lebar 20 $\mathrm{m}$. Saat berlangsung permainan, masingmasing tim terdiri atas 6 pemain dan 1 penjaga gawang. Waktu yang digunakan adalah 2 x 30 menit. Masing-masing tim terdiri dari 12 pemain. Namun, hanya 7 pemain yang ada di lapangan termasuk dengan seorang penjaga gawang. Selebihnya adalah pemain pengganti selama permainan berlangsung. Mereka masuk dan meninggalkan lapangan permainan dari daerah pergantian. Pemain bergantian posisi antara menyerang dan bertahan, tergantung 
dari penguasaan bola. Menurut Rachman \& Susanto dalam Sridadi \& Utama (2016) pada dasarnya permainan bola tangan terdiri atas beberapa teknik dasar seperti warming-up, attacking, defencing, dan fast break exercise namun dalam permainan hanya tiga teknik dasar yang paling sering digunakan, diantaranya; (1) teknik dribbling yaitu upaya pemain untuk membawa bola mendekati daerah pertahanan lawan dengan cara memantulkan bola ke lantai, (2) teknik passing yaitu upaya memberikan bola kepada teman dengan menggunakan satu atau dua tangan, (3) teknik shooting atau menembak bola ke gawang.

Bola tangan (handball) diartikan sebagai permainan beregu yang menggunakan bola sebagai alatnya dan dimainkan dengan menggunakan satu atau kedua tangan. Bola tersebut dapat dilempar, dipantulkan, atau ditembakkan. Induk organisasi dari bola tangan ini adalah International Handball Federation (IHF) dan di Indonesia sendiri adalah Asosiasi Bola Tangan Indonesia (ABTI). Tujuan dari permainan ini adalah memasukkan bola sebanyak - banyaknya ke gawang lawan, dan mencegah agar tim lawan tidak dapat memasukkan bola ke gawang kita sendiri. Kunci keberhasilan agar dapat bermain dengan baik, seseorang harus mengerti dan benar - benar dapat menguasai teknik - teknik dasar yang ada seperti passing, dribble, dan shooting. Melempar atau passing adalah pola gerak dasar yang dimaksudkan untuk melepaskan suatu objek menjauhi tubuh pelempar. Gaya melempar memang berbedabeda sesuai keperluannya tetapi pola dasarnya tetap konsisten atau sama. Bola dilempar kemudian bola tersebut harus ditangkap Sridadi \& Utama (2016). Pada cabang olahraga ini dominan bagian tubuh yang digunakan adalah menggunakan tangan, dan untuk menghasilkan poin yang banyak diperlukan kemampuan shooting yang keras dan terarah oleh seorang atlet, maka dari itu perlu dibentuk kekuatan otot lengan pada atlet-atlet handball demi mencapai hasil shooting yang maksimal.

Dari pembahasan tersebut dibutuhkan suatu proses latihan yang berulang dan kontinu baik dari segi mental, fisik, psikis dan lain sebagainya, akan tetapi pada penelitian ini menekankan pada pembentukan otot lengan. Seperti yang telah dikatan oleh Sukadiyanto \& Muluk (2011) latihan adalah penerapan dari suatu perencanaan untuk meningkatkan kemampuan berolahraga yang berisikan materi, teori, praktek, metode, dan aturan pelaksanaan sesuai dengan tujuan dan sasaran yang akan dicapai. Maka jelas bahwa latihan merupakan komponen utama untuk mencapai sebuah prestasi baik dalam olahraga tim maupun individu. Pembentukan kekuatan otot lengan diperlukan beberapa bentuk latihan, pada penelitian ini akan di uji cobakan menggunakan bentuk latihan crocodile push-up dan burpee, crocodile push-up mempunyai kelebihan dimana bentuk latihannya tidak monoton atau bentuk latihan yang dinamis menekankan pada otot-otot lengan sedangkan burpee merupakan latihan yang mempunyai kelebihan sama dinamis akan tetapi penekanan perkenaan ototnya lebih general seperti lengan serta gerakan lompat. Diharapkan dengan dua bentuk latihan tersebut dapat membentuk kekuatan otot serta menghasilkan shooting yang terarah. Penelitian ini menganalisis seberapa besar pengaruh latihan crocodile push-up dan burpee terhadap kekuatan otot lengan dan hasil shoooting handball mahasiswa STKIP PGRI Sumenep.

\section{METODE}

Penelitian ini menggunakan pendekatan kuantitatif menggunakan quasi experiment dengan rancangan penelitian matching only design (Maksum, 2012). Desain ini tidak menggunakan random sebagai cara memasukan subjek ke dalam atau dengan yang lain berdasarkan variabel tertentu. Desain penelitian ini dapat digambarkan seperti pada Gambar 1.

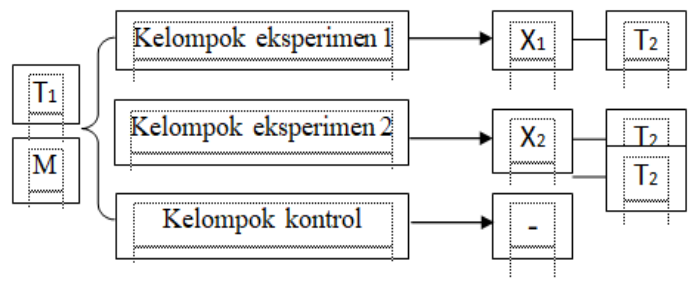

Gambar 1. Desain penelitian

\section{Keterangan:}


M : Matching

$\mathrm{T}_{1}$ : Pre-test kelompok eksperimen kekuatan otot lengan dan shooting handball

$\mathrm{T}_{2}$ : Post-test kelompok eksperimen kekuatan otot lengan dan shooting handbal

$\mathrm{X}_{1}$ : Treatment kelompok eksperiment crocodille push-up

$\mathrm{X}_{2}$ : Treatment kelompok eksperiment burpee

- $\quad$ : Tidak diberikan treatment/latihan

Langkah penelitian berdasarkan desain pada Gambar 1, yaitu kelompok eksperimen 1 diberi perlakuan $\left(\mathrm{X}_{1}\right)$, yaitu program latihan crocodile push-up dan kelompok eksperimen 2 diberi perlakuan $\left(\mathrm{X}_{2}\right)$, yaitu latihan burpee. Kelompok kontrol dengan program latihan konvensional, maksudnya latihan yang dilakukan sesuai dengan program latihan biasanya tanpa ada tambahan latihan crocodile push-up dan burpee. Setelah enam minggu pelatihan selanjutnya dilakukan posttest kepada ketiga kelompok $\left(\mathrm{T}_{2}\right)$.

Populasi dalam penelitian ini adalah Mahasiswa UKM Handball STKIP PGRI Sumenep. Sampel dalam penelitian berjumlah 30 Mahasiswa UKM STKIP PGRI Sumenep. Sebelum pengelompokan pada penelitian ini dilakukan tes awal (pretest) pada atlet. Hasil pretest atlet akan urut mulai dari skor tes awal tertinggi hingga yang memiliki skor yang terendah. Pembagian sampel pada setiap kelompok menggunakan teknik ordinal pairing. Ordinal pairing adalah teknik pengelompokan subjek dengan menggunakan sistem ranking, kemudian menempatkan sampel pada masing-masing kelompok dengan mengikuti pola "huruf S". Dengan tujuan untuk penggunaan ordinal pairing adalah untuk menyamarkan kemampuan subyek di masing-masing kelompok. Berdasarkan teknik ordinal pairing maka sampel dalam penelitian ini dikelompokkan sebagai Kelompok I (Eksperimental) sebanyak 10 atlet (diberi perlakuan latihan Crocodile pushup), Kelompok II (Eksperimental) sebanyak 10 atlet (diberi perlakuan latihan Burpee), dan
Kelompok III (Kontrol) sebanyak 10 atlet (tidak diberi perlakuan/latihan konvensional).

Data dianalisis secara statistik untuk mengetahui pengaruh latihan crocodile pushup dan burpee terhadap kekuatan otot lengan dan hasil shooting handball. Uji-t paired sample test dikonduksikan dengan uji prasyarat homogenitas dan normalitas pada taraf signifikansi $\alpha=0.05$. Setelah itu menggunakan analisis MANOVA (Multivariate Analysis of Variance) pada hipotesis yang membandingkan pengaruh antar latihan yang diterapkan dari dua kelompok eksperimen.

\section{HASIL DAN PEMBAHASAN}

Hasil pretest dan posttest Kekuatan Otot Lengan dengan memberikan perlakuan Crocodile pus-up dan Burpee pada 10 Mahasiswa STKIP PGRI Sumenep disajikan pada Tabel 1.

Tabel 1. Hasil Pretest dan posttest Kekuatan Otot Lengan

\begin{tabular}{|l|c|c|c|c|c|c|}
\hline \multirow{2}{*}{ Deskripsi } & \multicolumn{2}{c|}{ Crocodile Push-Up } & \multicolumn{2}{c|}{ Burpee } & \multicolumn{2}{c|}{ Kontrol } \\
\cline { 2 - 7 } & Pretest & Posttest & Pretest & Posttest & Pretest & Posttest \\
\hline Rata-Rata & 28.10 & 37.30 & 32.30 & 37.90 & 31.60 & 36.90 \\
\hline Standar Deviasi & 6.41 & 6.11 & 8.69 & 7.72 & 8.15 & 8.68 \\
\hline
\end{tabular}

Berdasarkan penghitungan pada Tabel 1 di atas, hasil pretest kelompok Crocodille memperlihatkan bahwa nilai rata-rata 28.10 dengan simpangan baku 6.41, kemudian hasil pretest kelompok Burpee menunjukkan hasil rata-rata 32.90 dengan simpangan baku 8.69 dan yang terakhir hasil pretest kelompok kontrol menunjukkan hasil rata-rata 31.60 dengan simpangan baku 8.15. Hal ini juga menunjukkan bahwa nilai rata-rata pretest dapat dikatakan ideal dikarenakan nilai ratarata tidak lebih besar dari nilai simpangan baku, sehingga memenuhi uji prasyarat data untuk dilakukan penghitungan selanjutnya. Hasil posttest kelompok crocodille memperlihatkan bahwa nilai rata-rata 37.30 dengan simpangan baku 6.11, kemudian hasil posttest kelompok Burpee menunjukkan hasil rata-rata 37.90 dengan simpangan baku 7.72 dan yang terakhir hasil posttest kelompok kontrol menunjukkan hasil rata-rata 36.90 dengan simpangan baku 8.68. Hal ini juga menunjukkan bahwa nilai rata-rata posttest dapat dikatakan ideal dikarenakan nilai ratarata tidak lebih besar dari nilai simpangan 
baku, sehingga memenuhi uji prasyarat data untuk dilakukan penghitungan selanjutnya.

Hasil pretest dan posttest Flying shoot Shooting Handball dengan memberikan perlakuan Crocodile pus-up dan Burpee pada 10 Mahasiswa STKIP PGRI Sumenep disajikan pada Tabel 2 .

Tabel 2. Hasil Pretest dan posttest Flving shoot Shooting Handball

\begin{tabular}{|l|c|c|c|c|c|c|}
\hline \multirow{2}{*}{ Deskripsi } & \multicolumn{2}{c}{ Crocodile Push-Up } & \multicolumn{2}{|c|}{ Burpee } & \multicolumn{2}{c|}{ Kontrol } \\
\cline { 2 - 7 } & Pretest & Posttest & Pretest & Posttest & Pretest & Posttest \\
\hline Rata-Rata & 4.67 & 5.73 & 5.02 & 5.64 & 5.03 & 5.71 \\
\hline Standar Deviasi & 0.94 & 0.98 & 1.11 & 0.97 & 0.80 & 0.86 \\
\hline
\end{tabular}

Hasil pretest kelompok Crocodille pada Tabel 2 menunjukkan bahwa nilai ratarata 4.67 dengan simpangan baku 0.94, kemudian hasil pretest kelompok Burpee menunjukkan hasil rata-rata 5.02 dengan simpangan baku 1.11 dan yang terakhir hasil pretest kelompok kontrol menunjukkan hasil rata-rata 5.03 dengan simpangan baku 0.80 . Hal ini juga menunjukkan bahwa nilai ratarata pretest dapat dikatakan ideal dikarenakan nilai rata-rata tidak lebih besar dari nilai simpangan baku, sehingga memenuhi uji prasyarat data untuk dilakukan penghitungan selanjutnya. Hasil posttest kelompok crocodille memperlihatkan bahwa nilai rata5.73 dengan simpangan baku 0.98 , kemudian hasil posttest kelompok Burpee menunjukkan hasil rata-rata 5.64 dengan simpangan baku 0.97 dan yang terakhir hasil posttest kelompok kontrol menunjukkan hasil rata-rata 5.71 dengan simpangan baku 0.86. Hal ini juga menunjukkan bahwa nilai rata-rata posttest dapat dikatakan ideal dikarenakan nilai rata-rata tidak lebih besar dari nilai simpangan baku, sehingga memenuhi uji prasyarat data untuk dilakukan penghitungan selanjutnya.

Sebagai uji prasyarat pengujian hipotesis, dalam penelitian ini dilakukan uji normalitas dan homogenitas. Hasil kedua uji ini disajikan pada Tabel 3, Tabel 4, dan Tabel 5.

\begin{tabular}{|c|c|c|c|c|c|c|}
\hline \multirow{2}{*}{ Kelompok } & \multicolumn{2}{|c|}{ Crocodile Push-Up } & \multicolumn{2}{|c|}{ Burpee } & \multicolumn{2}{|c|}{ Kontrol } \\
\hline & Pretest & Posttest & Pretest & Posttest & Pretest & Posttest \\
\hline Asymp. Sig & 0.200 & 0.200 & 0.200 & 0.200 & 0.200 & 0.200 \\
\hline alpha & 0.05 & 0.05 & 0.05 & 0.05 & 0.05 & 0.05 \\
\hline
\end{tabular}

\begin{tabular}{|c|c|c|c|c|c|c|}
\hline \multirow{2}{*}{ Kelompok } & \multicolumn{2}{|c|}{ Crocodile Push-Up } & \multicolumn{2}{|c|}{ Burpee } & \multicolumn{2}{|c|}{ Kontrol } \\
\hline & Pretest & Posttest & Pretest & Posttest & Pretest & Posttest \\
\hline Asymp. Sig & 0.200 & 0.200 & 0.200 & 0.200 & 0.200 & 0.142 \\
\hline alpha & 0.05 & 0.05 & 0.05 & 0.05 & 0.05 & 0.05 \\
\hline Tabel 5. Ha & Homogenita & as Kekutan & t Lengar & dan Flyil & hoot Sh & ting Hanb \\
\hline Data & Asymp. Sig & alpha & Keterar & gan & & \\
\hline Pretest & 0.765 & 0.05 & Homo & & & \\
\hline Posttest & 0.690 & 0.05 & Homo & & & \\
\hline
\end{tabular}

Hasil pada Tabel 3 menunjukkan bahwa besarnya nilai Asymp. Sig. (2 tailed) dari ketiga kelompok menunjukkan angka yang lebih besar dari 0.05. Dengan begitu sesuai dengan kriteria pengujian bahwa data dari ketiga kelompok tersebut berdistribusi normal. Tabel 4 menunjukkan bahwa besarnya nilai Asymp. Sig. (2 tailed) dari ketiga kelompok menunjukkan angka yang lebih besar dari 0.05. Dengan begitu sesuai dengan kriteria pengujian bahwa data dari ketiga kelompok tersebut berdistribusi normal. Hasil uji homogenitas pada Tabel 5 menunjukkan bahwa angka signifikansi pada data pretest antara dua kelompok eksperimen dan kelompok kontrol sebesar 0.765, hal ini menunjukkan bahwa taraf signifikasi $0.765>0.05$ maka dapat disimpulkan bahwa data tersebut homogen. Sedangkan pada data posttest dari dua kelompok eksperimen dan kelompok kontrol diperoleh angka sebesar 0.690, hal ini menunjukkan bahwa taraf signifikasi $0.690>0.05$ maka dapat disimpulkan bahwa data tersebut homogen, dengan begitu penghitungan dapat dilanjutkan untuk uji hipotesis. Uji hipotesis disajikan pada Tabel 6, Tabel 7, dan Tabel 8.

Tabel 6. Uji Beda Paired Sampel t Test Pretest Kelompok Crocodille Push-Up terhadap Kekuatan Otot Lengan dan Flying Shoot Shooting Handball

\begin{tabular}{|c|c|c|c|c|c|}
\hline Pair & Mean & $\begin{array}{c}\text { Std. } \\
\text { Deviasi }\end{array}$ & $\mathrm{t}$ & df & $\begin{array}{l}\text { Sig. } \\
\text { (2tailed) }\end{array}$ \\
\hline $\begin{array}{l}\text { - Pretest-Posttest Kelompok Crocodille } \\
\text { Push-Up Terhadap Kekuatan Otot } \\
\text { Lengan. }\end{array}$ & 9.200 & 4.022 & 7.233 & 9 & 0.000 \\
\hline $\begin{array}{l}\text { - Pretest-Posttest Kelompok Crocodille } \\
\text { Push-Up Terhadap Flying Shoot } \\
\text { shooting Handball. }\end{array}$ & 1.054 & 0.238 & 13.976 & 9 & 0.000 \\
\hline
\end{tabular}

Hasil pada Tabel 6 di atas terlihat bahwa skor t hitung $7.233 \mathrm{df}=9$ diperoleh dari rumus $\mathrm{N}-1$, dan $\mathrm{t}$ tabel pada taraf signifikasi sebesar 0.05 sebesar 1.83311 . Untuk mengetahui ada atau tidaknya pengaruh pemberian Crocodile Push-Up dan Burpee terhadap Kekuatan Otot Lengan dan 
Hasil Flying shoot shooting handball dapat diketahui melalui dengan dua cara, yaitu: (1) dengan melihat signifikasi yang diperoleh dalam penghitungan uji t dengan SPSS v.22. Berdasarkan tabel 6 di atas terlihat bahwa sig. (2-tailed) sebesar 0.000 , itu artinya taraf siginifikasi $\quad 0.000<0.05$. (2) Dengan membandingkan nilai t hitung dengan t tabel, berdasarkan tabel 6 di atas terlihat bahwa $\mathrm{t}$ hitung $7.233<\mathrm{t}$-tabel $=1.83311$. Melihat dari dua cara pengambilan keputusan di atas tersebut, dapat ditarik kesimpulan bahwa Ho diterima, artinya terdapat perbedaan antara Crocodile Push-Up terhadap Kekuatan Otot Lengan. Hasil pada Tabel 6 menunjukkan skor $\mathrm{t}$ hitung $13.976 \mathrm{df}=9$ diperoleh dari rumus $\mathrm{N}-1$, dan t tabel pada taraf signifikasi sebesar 0.05 sebesar 1.83311. Hasil pada Tabel 6 menunjukkan bahwa bahwa Ho diterima, artinya terdapat perbedaan antara Crocodile push-Up terhadap Flying Shoot Shooting Handball.

Tabel 7. Uji Beda Paired Sampel t Test Pretest Kelompok Burpee Terhadap Kekuatan Otot Lengan dan Flying Shoot Shooting Handball

\begin{tabular}{|l|c|c|c|c|c|}
\hline \multicolumn{1}{|c|}{ Pair } & Mean & $\begin{array}{c}\text { Std. } \\
\text { Deviasi }\end{array}$ & $\mathrm{t}$ & $\mathrm{df}$ & $\begin{array}{c}\text { Sig. } \\
\text { (2tailed) }\end{array}$ \\
\hline $\begin{array}{l}\text { - Pretest-Posttest Kelompok Burpee } \\
\text { Terhadap Kekuatan Otot Lengan }\end{array}$ & 5.600 & 2.412 & 7.339 & 9 & 0.000 \\
$\begin{array}{l}\text { - Pretest-Posttest Kelompok Burpee } \\
\text { Terhadap Flying Shoot shooting }\end{array}$ & 0.625 & 0.362 & 5.457 & 9 & 0.000 \\
Handball & & & & & \\
\hline
\end{tabular}

Hasil pada Tabel 7 di atas terlihat bahwa skor t hitung $7.339 \mathrm{df}=9$ diperoleh dari rumus $\mathrm{N}-1$, dan $\mathrm{t}$ tabel pada taraf signifikasi sebesar 0.05 sebesar 1.83311 . Untuk mengetahui ada atau tidaknya pengaruh pemberian Crocodile Push-Up dan Burpee terhadap Kekuatan Otot Lengan dan Hasil Flying shoot shooting handball dapat diketahui melalui dengan dua cara, yaitu: (1) dengan melihat signifikasi yang diperoleh dalam penghitungan uji t dengan SPSS v.22. Berdasarkan Tabel 7 di atas terlihat bahwa sig. (2-tailed) sebesar 0.000, itu artinya taraf siginifikasi $0.000<0.05$. (2) Dengan membandingkan nilai $\mathrm{t}$ hitung dengan $\mathrm{t}$ tabel, berdasarkan Tabel 7 di atas terlihat bahwa t hitung 7.339<t-tabel $=1.83311$. Melihat dari dua cara pengambilan keputusan di atas tersebut, dapat ditarik kesimpulan bahwa Ho diterima, artinya terdapat perbedaan antara Burpee terhadap Kekuatan Otot Lengan.
Tabel 8. Uji Beda Paired Sampel t Test Pretest Kelompok Kontrol Terhadap Kekuatan Otot Lengan dan Flying Shoot Shooting Handball

\begin{tabular}{|l|c|c|c|c|c|}
\hline \multicolumn{1}{|c|}{ Pair } & Mean & $\begin{array}{c}\text { Std. } \\
\text { Deviasi }\end{array}$ & t & df & $\begin{array}{c}\text { Sig. } \\
\text { (2tailed) }\end{array}$ \\
\hline $\begin{array}{l}\text { - Pretest-Posttest Kelompok Kontrol } \\
\text { Terhadap Kekuatan Otot Lengan }\end{array}$ & 5.300 & 2.869 & 5.841 & 9 & 0.000 \\
\hline $\begin{array}{l}\text { - Pretest-Posttest Kelompok Kontrol } \\
\text { Terhadap Flying Shoot shooting }\end{array}$ & 0.680 & 0.417 & 5.146 & 9 & 0.001 \\
\hline Handball & & & & & \\
\hline
\end{tabular}

Hasil pada Tabel 8 di atas terlihat bahwa sig. (2-tailed) sebesar 0.000 , itu artinya taraf siginifikasi $0.000<0.05$, lalu dengan membandingkan $\mathrm{t}$ hitung dengan $\mathrm{t}$ tabel, berdasarkan Tabel 8 di atas terlihat bahwa $\mathrm{t}$ hitung $=5.841>\mathrm{t}$-tabel $=1.83311$. Melihat dari dua cara pengambilan keputusan di atas tersebut, dapat ditarik kesimpulan bahwa kelompok kontrol mengalami peningkatan, apabila dilihat dari hasil rata-rata kelompok eksperimen lebih besar dibandingkan dengan kelompok kontrol, sehingga dapat ditarik kesimpulan bahwa ada pengaruh yang signifikan. Dari hasil ini terlihat bahwa sig. (2-tailed) sebesar 0.000 , itu artinya taraf siginifikasi $\quad 0.000<0.05, \quad$ lalu dengan membandingkan $\mathrm{t}$ hitung dengan $\mathrm{t}$ tabel, berdasarkan Tabel 8 di atas terlihat bahwa $\mathrm{t}$ hitung $=5.146>\mathrm{t}$-tabel $=1.83311$. Melihat dari dua cara pengambilan keputusan di atas tersebut, dapat ditarik kesimpulan bahwa kelompok kontrol mengalami peningkatan, apabila dilihat dari hasil rata-rata kelompok eksperimen lebih besar dibandingkan dengan kelompok kontrol sehingga dapat ditarik kesimpulan bahwa ada pengaruh yang signifikan.

Hasil uji hipotesis pertama, yaitu uji analisis yang digunakan untuk mengetahui kemampuan Kekuatan Otot Lengan dan Hasil Flying Shoot Shooting Hanball Mahasiswa STKIP PGRI Sumenep dipengaruhi oleh latihan Crocodile Pus-Up dan Burpee berdasarkan pretest dan posttest menunjukkan bahwa rata-rata posttest $9.200>5.600$ dan $1.054>0.625$ dari rata-rata pretest. Hal ini menunjukan terdapat peningkatan yang signifikan antara pretest dan posttest terhadap Flying Shoot Shooting Handball yang dipengaruhi oleh perlakuan Crocodile pushup dan burpee terhadap Kekuatan Otot Lengan dah hasil Flying Shoot Shooting handball Mahasiswa STKIP PGRI Sumenep. Menurut Tamakrin (2014) Burpee adalah 
salah satu latihan olahraga tanpa peralatan yang melatih seluruh badan dan merupakan latihan kardiaovaskular yang baik dan efektif untuk dilakukan. Pemberian pelatihan burpee akan meningkatkan unsur kebugaran jasmani seperti kekuatan otot tungkai, fleksibilitas, koordinasi serta keseimbangan dinamis sehingga berdampak terhadap peningkatan kelincahan kaki. Uji hipotesis kedua, yaitu dari hasil analisis terlihat bahwa t-hitung $7.233<7.339$ dan $13.976>5.457$ berdasarkan data tersebut, dapat ditarik kesimpulan bahwa ada pengaruh latihan Crocodile Push-up dan Burpee terhadap Kekuatan Otot Lengan dah hasil flying Shoot Shooting Handball Mahasiswa STKIP PGER Sumenep. Yang diberi latihan selama 6 minggu Bompa \& Half (2009) menyatakan power adalah hasil dari kedua kemampuan kecepatan maksimal dan kekuatan maksimal dalam waktu yang sesingkat mungkin. Untuk melakukan crocodile push-up dan burpee sangat berguna untuk meningkatkan kemampuan otot lengan baik kekuatan, kecepatan dan power, karena pada dasarnya latihan ini mengutamakan penggunaan tangan sebagai tumpuan utama untuk latihan. Uji hipotesis ketiga, yaitu dari hasil perhitungan Crododile push-up dan Burpee menunjukkan bahwa latihan kekuatan otot lengan dan hasil Flying Shoot Shooting Handball Mahasiswa STKIP PGRI Sumenep mengalami peningkatan yang signifikan. Setelah diberi latihan kekuatan otot lengan dan hasil Flying Shoot Shooting Handball selama delapan belas kali pertemuan dengan porsi yang sama selama perlakuan, sehingga pada kelompok eksperimen terjadi peningkatan yang signifikan. dilihat dari data mentah pretest dan posttest kelompok kontrol dan eksperimen tidak ada atlet yang mencapai katagori baik, akan tetapi beberapa mengalami peningkatan namun ada juga yang mengalami penurunan. Sehingga dapat disimpulkan bahwa ada pengaruh latihan Crocodile Push-Up dan Burpee terhadap kekuatan otot lengan dan hasil Flying Shoot Shooting Handball Mahasiswa STKIP PGRI Sumenep.

\section{KESIMPULAN}

Hasil penelitian tentang pengaruh latihan Crocodile Push-up dan Burpee terhadap Kekuatan Otot Lengan dah hasil flying Shoot Shooting Handball Mahasiswa STKIP PGRI Sumenep. Maka dapat disimpulkan bahwa terdapat pengaruh yang signifikan dari latihan Crocodile push-up dan Burpee, dengan mode kesimpulan; a) pengaruh latihan crocodile push up terhadap kekuatan otot lengan menunjukkan bahwa $0,00<0,05$ berdasarkan hasil ini maka di simpulkan bahwa terdapat pengaruh yang signifikan; b) pengaruh latihan crocodile push up terhadap hasil shooting handball menunjukkan bahwa $0,00<0,05$ berdasrkan hasil ini maka di simpulkan bahwa terdapat pengaruh yang signifikan; c) pengaruh latihan burpee terhadap kekuatan otot lengan menunjukkan bahwa $0,00<0,05$ berdasrkan hasil ini maka di simpulkan bahwa terdapat pengaruh yang signifikan; dan d) pengaruh latihan burpee terhadap hasil shooting handball menunjukkan bahwa $0,00<0,05$ berdasarkan hasil ini maka di simpulkan bahwa terdapat pengaruh yang signifikan.

\section{SARAN DAN REKOMENDASI}

Penelitian ini dapat dijadikan instrumen ekstrakurikuler agar nantinya mereka lebih giat dan termotivasi untuk mengembangkan bakat mereka dengan berlatih secara bersungguh-sungguh. Selain itu, hasil dari penelitian inid apat dijadikan referensi dalam latihan, terutama latihan yang bertujuan untuk melatih ataupun memaksimalkan kemampuan fisik atau biomotor. Hasil penelitian ini diharapkan dapat menambah wawasan Mahasiswa bidang olahraga, atlet, pelatih serta pembina olahraga maupun seluruh pelaku olahraga pada umumnya dalam mengembangkan prestasi terutama pada aspek fisik dan biomotor.

\section{DAFTAR PUSTAKA}

Andi, P. (2011). Analisis Kerja Pemerintah Daerah Kabupaten Karanganyar Dilihat Dari Rasi Pendapatan Daerah Pada APBD 2006-2008. Skripsi. Surakarta. Universitas Muhammadiyah Surakarta. 
Ambarukmi, D. H. Pasurney. P. Sidik. D. Z. Irianto, D. P. Dewanti. Sunyoto. Sulistyanto. D. \& Harahap. (2007). Pelatihan Pelatih Fisik Level 1. Jakarta Asdep Pengembangan Tenaga dan Pembinaan Keolahragaan Deputi Bidang Peningkatan Prestasi dan IPTEK Olahraga Kementrian Pemuda dan Olahraga.

Arikonto, S. (2010). Prosedur Penelitian Suatu Pendekatan Praktik. Jakarta: Rineka Cipta.

Andini, A., \& Indra, E. N. (2016). Perbedaan pengaruh frekuensi latihan senam aerobic terhadap penurunan persentase lemak tubuh dan berat badan pada members wanita. Medikora. 5(1). 3951.

Azwar, S. (2017). Metode Penelitian Psikologi. Yogyakarta: Pustaka Belajar.

Calnton dan Dwight. 1997. Team Handball: Steps To Success: Series 3 Canada: Human Kinetics

Bompa, T.O,. \& Haff G. G. (2009).Periodization Theory and Methodology of training. USA: Human Kinematics.

Gioftsidou, A. et al. (2012) 'The Effects Of Balance Training On Balance; Exercise And Quality of Life, 4(2),1522.

Haris. A., Harwanto, \& Hari, K. (2020). Development of Burpee and Crocodile Push-up Combination Exercise Model through Arm Muscle Strength and 50 Meters' Freestyle Swimming Speed. Journal of Innovative Science and Research Technology, 5, 2456-2165.

Harsono. (2017). Kepelatihan Olahraga. Bandung. PT Remaja Rosdakarya.

Kusnanik, N.W., Nasution, J., dan Hartono, S. (2011). Dasar-dasar Fisiologi Olahraga. Unesa: Unesa University Press.

Mahendra, A. (2000). Bola tangan: Departemen Pendidikan dan Kebudayaan Direktorat Jendral Pendidikan Dasar dan Menengah Bagian Proyek Penataran Guru SLTP Strata D-III.
Maksum, A. (2012). Metodologi Penelitian Dalam Olahraga. Surabaya: Unesa University Press.

Mathews, G., dkk. (2000). Human Performance Cognition, Stress And Indivifual Differences. Philadelphia: Psychologi Press.

Mylsudayu, A., \& Kurniawan F. (2015). Ilmu Kepelatihan Dasar. Bandung: Alfabet.

Naclerio, Fernando. 2013. Aplied Periodization: a Methodological Approach. J. Hum. Sport Exerc. 8(2). 350-366.

Neck, E. (2013). Tips Latihan Fitness. Diakses tanggal 5-13-2018. Ekoncerita.blogspot.co.id/2013/03/5variasi-latihan-push-up_4035.html.

Nurhasan. (2011). Tips Praktis Menjaga Kebugaran Jasmani. Gresik: Abil Pustaka.

Purnama dan Wednesday (2015). Ukuran Lapangan Bola Tangan. Diperoleh dari https://www.volimaniak.com

Roesdiyanto \& Budiyanto, S. 2008. "Dasardasar Kepelatihan Olahraga". Malang: Laboratorium Ilmu Keolahragaan Universitas Malang.

Sridadi. A M. \& Utama. B. (2016). Pengembangan Instrumen Tes Keterampilan Dasar Bolatangan Bagi Mahasiswa. Jurnal Pendidikan Jasmani Indonesia. 12(2), 111-119.

Sriundy, M. I M. (2015). Metodologi penelitian. Surabaya: Unesa University Press.

Strand, B. and Wilson, R. (1993). Assessings sport skill. Human Kinetics Publishers.

Sugiyono. 2013. Metode Penelitian Pendidikan. Bandung: Alfabeta.

Sukadiyanto dan Muluk, D. (2011). Pengantar Teori dan Metodologi Melatih Fisik. Bandung: Lubuk Agung.

Tri, W. (2011). Kepuasan Keluarga Pasien Terhadap Waktu Tunggu Pelayanan di Instalansi Rawat Jalan Rumah Sakit Jiwa Provinsi Kalimantan Barat. Jurnal Kesehtan Masyarakat Universitas Gajah Mada 4 (2). 
Wahono.T. Syafrial, \& Arwin (2017).

Kontribusi Kekuatan Otot Lengan dan

Kelincahan Terhadap Half Nelson

Pada Atlet Gulat Provinsi Bengkulu.

Jurnal Ilmiah Pendidikan Jasmani, 1, 2477-3311. 